\title{
5. Situated Learning in Open Communities: The TED Open Translation Project
}

\section{Lidia Cámara de la Fuente and Anna Comas-Quinn}

Online communities where users can engage as both consumers and producers of content offer increasing opportunities for teachers and learners to connect formal and informal learning, often through open practice.

TED Translators, an online community of volunteers involved in the crowd-sourced translation of audiovisual open content, provides a good opportunity for teachers to involve their students in completing authentic tasks that make a real contribution to society, in this case, disseminating ideas across languages and cultures whilst practicing the skill of translating video subtitles. Using a qualitative approach based on the analysis of participants' narratives, we explored the experiences of situated learning within a community of practice as part of a pedagogy that seeks to exploit the intersection between learning in formal and informal contexts. We focused on students' perceptions of the learning derived from participation in TED Translators, and the role of this activity in the training of translators, and found that participants valued the learning of a new skill and the often serendipitous knowledge they gained about other topics, and were mostly positive about the role of this kind of activity in translator education. 


\section{Introduction}

The democratizing effect of the internet has blurred the lines between experts and non-experts in many fields, and changed the concept of knowledge and how and where learning takes place (Tapscott and Williams, 2008). An increasing number of online communities, where users can engage as both consumers and producers of content, offer extensive opportunities for teachers and learners to connect formal and informal learning, often through open practice (Beetham, Falconer, McGill and Littlejohn, 2012) as exemplified by the Wikipedia Education Programme. ${ }^{1}$

In the field of translation, technology is shaping content (web, app and games), but also substantially altering the landscape of practice (post-editing of machine translation and online volunteer translation). Exploring the boundary between online volunteer translation and translation education may yield important insights into how pedagogy responds to these changes in practice.

This chapter explores the relationship between learning and participation in an online volunteer community, TED Translators, involved in the crowd-sourced translation of audiovisual open content. Translation graduates were introduced to the translation of subtitles to develop subtitling, digital and collaborative learning skills. This research set out to capture and describe the experiences of participants undertaking an authentic, experiential, situated activity (Kiraly, 2015), and to explore the feasibility of using online volunteer translation communities as part of translators' training, possibly as an intermediate step between classroom-based instruction and graduate placements or internships.

The next section outlines the main theoretical principles on which authentic, experiential and situated learning is based, including the conceptualization of learning that underpin different views of education practice. The context section describes the setting for the study, TED Translators, and what research on TED Translators tells us about volunteer motivation.

The methodology section describes the study undertaken by the researchers, its design, methodology, participants, data collection tools

1 https://outreach.wikimedia.org/wiki/Education 
and analytic method. The findings are then presented and discussed in relation to theories of learning in formal and informal contexts, and to how individuals conceptualize the learning they derive from different activities.

The contribution closes with some reflections on the significance of the investigation, its limitations, and ideas for further research in this area.

\section{Theoretical Framework}

Efforts have been made in translation education to replace traditional instructivist teaching methods, where the teacher prepares and serves the information for the student to "absorb", with pedagogies that are more in line with current research on learning and teaching (Orrego Carmona, 2013: Mitchell-Schuitevoerder, 2014, Kiraly, 2005, 2012). These are often project-based and driven by the need to keep up with technological change and its effects on translation. They are also typically anchored in a constructivist paradigm, based on the notion, crystallized in the metaphor of learning as participation (Sfard, 1998), that knowledge is subjective and constructed through participation in social and cultural settings.

Understanding learning as a situated experience, that is, one that arises from involvement and co-participation in a social context and with the community that generates and uses that learning (Lave and Wenger, 1991), underpins this socio-constructivist approach to translator education advocated by some scholars (Risku, 2010; Kiraly, 2012).

Situated learning focuses on participation in groups and situations that allow learners to become aware of, and eventually contribute to, the generation of knowledge relevant to them. Lave and Wenger (1991) called these "communities of practice", groups described by Wenger (1998) as sharing an interest in improving how they carry out an activity, whether they intentionally set out to learn or not. Learning in a community of practice is a dynamic concept linked to the relations within the community and to individuals' drive to becoming a full member of that community.

Research on communities of practice has evolved to explore how these interact with each other in full "landscapes of practice", 
a metaphor used to describe "a complex system of communities of practice and the boundaries between them" (Wenger-Trayner and Wenger-Trayner, 2015, p. 13). Professional occupations fit well into this description with their many communities of practitioners, researchers, managers, associations, educators, etc. that are linked in different ways to each profession. Landscapes of practice are dynamic and contested, as different communities compete for power and the control of resources or legitimate discourse and gatekeeping. Still, landscapes are diverse, and each practice has its own culture and its own knowledge, although "[w] hether the competence of a community is recognized as knowledge depends on its position in the politics of the landscape". (ibid., p. 16). The practices developed by online volunteer translation communities are a good example of this, given the controversial nature of volunteer translation viewed by some scholars as a practice that reinforces the notion that translation can be free ( $\mathrm{O}^{\prime}$ Hagan, 2012) and hence is damaging to the profession.

The boundaries between practices and communities can cause tension and misunderstanding but can also function as triggers for reflection and innovation for those communities. More importantly these boundaries can be used in learning if educators can fathom the kinds of objects and activities that will help learners explore a boundary productively to trigger reflection on the practice of a community.

Beyond learning as participation, the metaphors of learning as becoming, and learning as expansion or transformation (Hager and Hodkinson, 2009) have also been associated with situated, authentic learning, and are applied to the process of generating knowledge whilst carrying out an activity, a process that transforms participants, activity and context, and creates new understandings that result in new ways of doing things (Engeström, 1987).

Similarly, in their theory of enactivism, Davis and Sumara (1997) propose that "cognition does not occur in minds or brains, but in the possibility for shared action" (p. 117). They consider thought as "dynamic and always in flux [...] always caught up in new learning" (p. 106) and therefore regard "student learning as dependent on, but not determined by, the teaching" (p. 115). Learning within the enactivist framework is seen as being "'occasioned' rather than 'caused' [...] dependent on, but not determined by, the teaching" (p. 115) and leading to transformation both in the agent (the learner) and the context. Building on Davis and 
Sumara's work, Kiraly's research on translator education also presents learning as "the result of the complex interplay of processes and only incidentally and occasionally the direct result of teaching" (2015, p. 28).

Some consideration must be given here to defining informal learning, understood as "all forms of intentional or tacit learning in which we engage either individually or collectively without direct reliance on a teacher or externally organized curriculum" (Livingston, 2006, p. 204). Informal learning can occur in multiple contexts (Bekerman, Burbules and Silberman Keller, 2006) and has been considered fundamental for existing formal learning in educational establishments (Coffield, 2000).

Vavoula (2004) offers the following typology of learning (see Figure 1), distinguishing according to whether the goals and processes are determined by the teacher or the learner, or not determined at all. This investigation focuses on the intentional and unintentional learning derived from participation in an open online volunteer community.

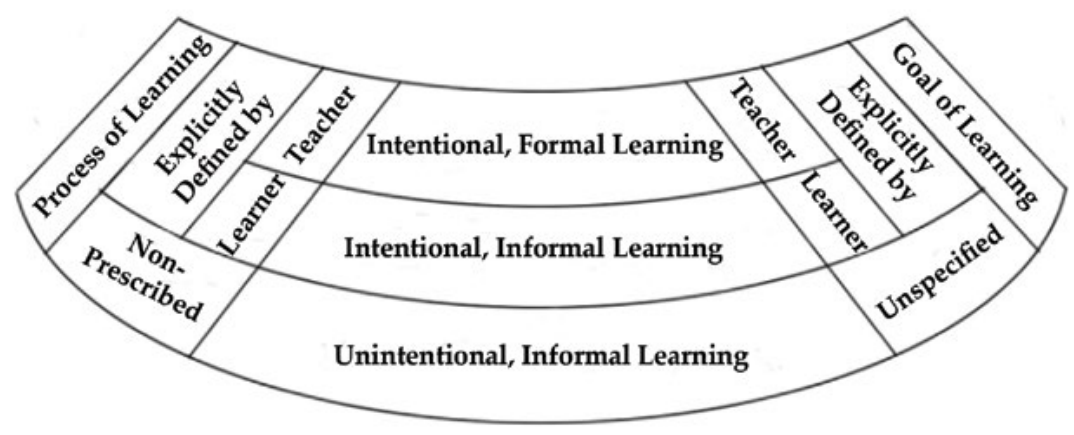

Figure 1. Typology of learning, based on the presence of, and control over, the object and the process of learning. Image from Vavoula (2004), all rights reserved

\section{TED and TED Translators}

TED stands for Technology, Entertainment and Design and "is a nonprofit devoted to spreading ideas, usually in the form of short, powerful talks". ${ }^{2}$ The official talks are given in English at conferences organized by TED, where experts share their knowledge in an engaging

2 http://www.ted.com/about/our-organization 
way. The short lectures are recorded, edited and published online by TED, making them accessible globally to a large audience. ${ }^{3}$ Local TEDx events following the same format are organized around the world, and also recorded and published through the TED platform.

As a public engagement initiative, TED's enormous reach and popularity has been attributed to the successful harnessing of technology to reduce the gap between experts and the public. Recent studies using bibliometric and webometric indicators have concluded that TED appears to be "one of the most prominent science popularization initiatives in history" (Sugimoto and Thelwall, 2013, p. 673).

To a large extent, the reach and impact of TED Talks can be attributed to the contribution of its volunteers, around 16,000, who transcribe the talks and translate the subtitles into more than 100 languages. Subtitles are essential to make the content accessible to those with hearing impairments, and can further benefit the one billion worldwide for whom English is a second or foreign language (Graddol, 2000). Providing subtitles in multiple languages is central to achieving TED's aspiration to "[reach] out to the 4.5 billion people on the planet who don't speak English", ${ }^{4}$ and making digital content available in multiple languages is key in promoting social inclusion (Helsper, 2008).

TED volunteers are the archetypal "prosumers" (Ritzer and Jurgenson, 2010) - consumers of content who also contribute to its production. Launched by TED in 2009 in response to user demand, TED Open Translation Project (TED OTP), later rebranded TED Translators, aimed at coordinating and facilitating the translation of subtitles by harnessing volunteers' enthusiasm. In that TED Translators easily fits Wenger's (1998) definition of a community of practice: it shares a very specific domain of interest, the translation of subtitles for TED talks; many of its members interact and support each other through the associated Facebook groups, local translatathon events, or by attending face-toface translation workshops at the annual TEDGlobal conferences. As a result of such close interactions members have developed a well-defined

3 "In the fall of 2012, TED Talks celebrated its one billionth video view [...] TED Talks continue to be watched around the world, with an average of 17 new page views a second". https://www.ted.com/about/our-organization/history-of-ted

4 http://blog.ted.com/2009/05/13/ted_open_trans 
shared practice and codified shared resources, such as guidelines made available through a wiki and video channels.

\section{Volunteers' profile}

There is no protocol for screening volunteers wishing to participate in the project. However, the skills shown in Figure 2 are a pre-requisite to participate as a translator or transcriber in TED Translators.

\section{Language and subtitling skills:}

- Volunteer translators should be fluently bilingual in both source and target languages.

- Volunteer transcribers should be fluent in the transcription language.

- Volunteer translators and transcribers should be knowledgeable of subtitling best practices.

Figure 2. Pre-requisite to participate as a translator or transcriber in TED Translators

Cámara (2014) reported on the profile of volunteers after placing her survey of participants $(\mathrm{N}=178)$ in the main Facebook TED Translators support group. The majority of respondents were aged 18-35, and the ratio of male to female was fairly balanced, except in the 18-25 segment, where there were twice as many men as women, and a high proportion of students, and in the 36-45 segment, where two thirds of respondents were female translators. A large number of professionals were working as translators, teachers, scientists, researchers, and engineers, or in the information sciences. The majority had some kind of academic qualification, and around a sixth were students. A third of respondents had professional translation skills, and three-quarters of all respondents had no qualification in subtitling before joining TED Translators. Amongst the quarter of respondents who claimed previous experience in subtitling, $86 \%$ had less than one year of experience in the field, and the majority had acquired that experience through other volunteering opportunities. 


\section{Volunteers' roles}

Volunteers can undertake several tasks including transcription, translation, revision and final approval before publication. Transcribers work in the original language of the talk, creating the subtitles that translators use as the basis for generating subtitles in other languages. Anyone can become a transcriber or translator in TED Translators, but it is recommended that only experienced volunteers, those who have already translated or transcribed at least ninety minutes of talks, undertake the revision phase, which consists of checking the transcript or translation for linguistic and technical accuracy.

The final check and approval for publication of the translation or transcript is carried out by volunteers who have applied for and been selected to the role of Language Coordinators on account of their experience and willingness to commit further to the project. Language Coordinators have an additional mentoring role and provide support to less experienced translators through language-specific Facebook groups. Quality control is thus inbuilt into the workflow (O'Hagan, 2012) and valuable feedback and support is provided by reviewers and language coordinators to translators and transcribers, in an apprenticeship style model (Lave and Wenger, 1991).

\section{Knowledge management}

TED has recognized the need for knowledge management tools to support and facilitate the work of volunteers. From 2011, the community has developed its own wiki, OTPedia, ${ }^{5}$ and a video tutorial channel, the TED Translators Learning Series, to collect and disseminate training material, style guides and best practice on all aspects of TED Translators work. ${ }^{6}$ Language Coordinators play a major role in capturing and shaping best practice, and providing feedback and suggestions to improve workflows and technical aspects (including the subtitle editor provided by the open source audiovisual translation platform Amara). ${ }^{7}$ There are also opportunities to meet at annual international workshops

5 http://translations.ted.org/wiki/Portal:Main

6 https://www.youtube.com/channel/UC6b3FWOn0YwVq0MHy0DtfBg

7 http://www.amara.org 
where Language Coordinators consolidate and extend their work, and strengthen the community.

\section{Research on TED Translators}

Learning and practising subtitling and the possibility of receiving feedback from more experienced translators are some obvious attractions for volunteers. In one of only two studies to date on translators' motivations in TED Translators, Cámara's (2014) respondents reported three main drivers to volunteering in TED Translators (\% who chose this answer):

- playing an active and interactive role in the expansion of the TED mission (75\%).

- making the most of their free time while enjoying themselves (53\%).

- acquiring subtitling skills and experiencing inter-cultural interactions in an informal learning context (53\%).

In another study, Olohan (2013) analyzed the discourse of volunteers through eleven posts published in the TED Translators blog in which volunteers explain why they translate for TED Translators. Acknowledging the limitations of her work, and in particular the bias in the data - as the posts are published by TED Translators and therefore likely to have been chosen because they chime with the mission of the organization - she nevertheless concluded that drivers for participation could be grouped into six categories:

- contributing to the TED mission of enabling others to benefit from TED and the sharing of ideas;

- effecting social change and "changing the world";

- altruistic behavior and the satisfaction derived from it (the "warm glow");

- the desire to be part of a community and connect with others;

- enhancing learning and knowledge (although not of translation skills but of the content of the talks); and

- the "fun" and "excitement" derived from translating and understanding.

Both studies concluded that learning is part of what motivates TED Translators volunteers to take part in this activity. The research presented 
in this chapter set out to find out what participants perceive they learned from the experience and how they view this learning. The results of this investigation will hopefully contribute to an understanding of the way the practices of online informal learning communities can be adopted in formal learning environments.

\section{Methodology}

In this study we set out to answer two questions:

- What do students learn from their engagement with TED Translators, and how do they learn?

- What benefits can translation students and translation professionals derive from participation in TED Translators?

This research is grounded in a constructivist paradigm, based on a view of knowledge as embodied and constantly changing, as the individuals and the complex ecology of relations they are part of also change (Davis and Sumara, 1997).

Given that only few studies on online volunteer translation communities have been carried out to date, an exploratory, qualitative approach anchored in a constructivist paradigm and based on the examination of subjective experience is appropriate to gain a better understanding of how learning is experienced and perceived by participants.

\section{Context and task}

For this investigation a self-paced supported six-week activity, ${ }^{8}$ subsequently shared as an Open Educational Resource, was designed and offered on a voluntary basis to a small group of Translation Studies graduates from a Spanish university. The tasks and supporting materials were posted in a dedicated, "private" ${ }^{\prime 9}$ Facebook group, and the researchers provided individual support to participants through

8 The activity can be found at http://loro.open.ac.uk/4802

9 Membership and content available by invitation only. See "What are the privacy settings for groups?" https://www.facebook.com/help/220336891328465 
the Facebook group, as they worked through the learning materials. These educational resources had been gathered from existing content (OTPedia and Learning Series videos) in a wrap-around learning design intended to promote learner autonomy and the efficient use of distributed resources. Participants were also encouraged to join the relevant Facebook TED Translators language groups for further support from regular TED Translators volunteers.

Both researchers are TED Translators volunteers (one a Language Coordinator since the role was established in 2011), and as such are aware that the interpretation of the findings may be colored by their insider status. Additionally, although their role in this study was that of facilitators and researchers, their status as academics in higher education institutions may have influenced the narrative constructions of participants, who had very recently finished their undergraduate studies (one participant was still a university student).

\section{Participants}

Participants were recruited by an English Lecturer at a Spanish university who leads a collaborative teaching innovation project. The self-selected group of students and former students participating in the study were given the opportunity to practice their English while acquiring translation, digital and online collaboration skills. Having been informed about the objectives and timeline for this project, six participants volunteered to take part in the activity, five recent graduates and an undergraduate. The group comprised six females and one male aged between eighteen and twenty-five, three of them based in Spain and three in the US. Four participants were still studying (one at undergraduate and three at postgraduate level), and two described themselves as professional translators, although indicating that they had not yet had experience as paid translators. Only one participant had some experience of translating subtitles, but not professionally. Out of the original six participants one female graduate participant dropped out early on in the study and five completed the task.

As the questionnaire revealed all participants showed high levels of familiarity with technology and social media both to seek and create information, and as effective tools to enhance their learning. 


\section{Data collection: instrument and procedure}

As both participants and researchers were spread across four countries in two continents online methods of data collection were adopted. Participants were asked to fill in a questionnaire at the start of the activity to provide general demographic data and to determine their previous experience with textual and audio-visual translation, as well as their self-reported attitudes towards technology and learning.

Given the pressures on participants' time and the fact that they had already devoted a substantial amount of time to completing the tasks, conducting individual interviews at the end of the activity was unfeasible. For this reason, the investigators devised an asynchronous method of data collection, inspired by the tool known as narrative frame (Barkhuizen and Wette, 2008), a method that provides "guidance and support in terms of both the structure and content of what is to be written", and ensures "that the content will be more or less what is expected (and required to address the research aims) and that it will be delivered in narrative form" (p. 376).

In this case, three sets of questions, encouraging a response in the form of a structured textual narrative, were posted in the Facebook group. Additional feedback was also requested in personal emails to allow individual participants to make further comments privately.

The three sets of questions, posted several days apart, addressed: 1) feedback on the activity itself, particularly views on how feasible it was to carry out the different tasks independently; 2) assessing participants' perceptions on what they had learnt; and 3) their views regarding the role of volunteer translation in relation to translator education and the practice of professional translation. The Findings and Discussion section is based on the last two groups of questions.

\section{Analytic method}

Participants' contributions to the final discussion were assembled into a textual corpus and analyzed thematically. Thematic analysis focuses on pinpointing, examining, and recording patterns (or "themes") within data. Themes are patterns across data sets that are important to the description of a phenomenon and are associated to a specific research 
question. Braun and Clarke (2006) describe this methodology as a twostep process: a first assessment of the data on a semantic level, that is, at the explicit or surface level of the information, followed by the identification of latent themes, "the underlying ideas, assumptions, and conceptualizations - and ideologies" (p. 84), their interpretation and their further investigation.

Thus a thematic analysis requires that the researchers identify themes that are either mentioned by several participants or are substantially developed by a single participant. Determining what is significant and constitutes a theme is one of the key challenges of the process, as researchers will inevitably bring their own agendas and biases to the analysis. In this case, both authors carried out the thematic analysis independently, and agreed the main themes within each set of questions. The following section contains the analysis and interpretation of the data illustrating the main themes identified with the most relevant quotes, and relating back the themes to the research questions and the literature.

\section{Findings and Discussion}

Participants were asked about their experience of the systems, procedures and instructions they used to complete the tasks. Most participants found the instructions clear and easy to follow, and reported that the experience of taking part in the activity had been good. Almost all of them also commented on how user-friendly the subtitle editor was, and how helpful they found the videos in preparing them to tackle the subtitling task. Two of them, however, did find the creation of an account difficult, and for one of them the technical issues marred the whole experience, leading to feelings of frustration:

The video did not help me [...] I tried over and over again, but I could not register. I contacted the Support Desk, and I asked for help in this Facebook group. [...] I spent more time trying to fix them [the registration problems] than actually translating the task. [...] the experience wasn't good and is still being confusing and frustrating. (P2 $)^{10}$

10 Here and hereafter each quote is attribute to a participant number in the study. 


\section{Learning}

The second set of questions probed participants' learning experiences, and their perceptions of what it was that they had learnt through their participation in this activity.

The skill of subtitling emerged strongly as the most easily recognized and fundamental aspect of the learning gained through participation in the activity. With one exception, this was the first subtitling task participants had ever attempted, and comments were overwhelmingly positive, with participants describing subtitling as "interesting" and "enjoyable". Still, the complexity of the task was acknowledged, with different aspects being identified, such as the difficulty in compressing text, regarded as "an interesting challenge that tested my imagination and resourcefulness" (P3), synchronizing the subtitles, "I think that was the part I enjoyed the most and Amara is a really great software for that" (P4), and "the importance of subtitling guidelines with regard to subtitle duration, line-breaking, etc". (P2). The experience also resulted in a new critical appreciation for the work involved in subtitling: "Having seen the work that goes behind good subtitles, I do now appreciate them more and I criticize them more every time I see bad ones" (P3).

It is interesting to note that the popular concept of learning as the acquisition of skills, what Hager and Hodkinson (2009) call the skills lens ${ }^{11}$ dominates participants' understanding of learning, a stance congruent with prevalent translation training models based on competences (PACTE, 2005; EMT, 2009).

Joining a community of practice and engaging in a dialogue with more experienced participants was valued, and participants commented on the benefits of having their work checked by more experienced translators and of engaging in a dialogue with them. For instance: "Knowing that my subtitles would be proofread by a professional ${ }^{12}$ translator before being published gave me confidence" (P2), and,

11 Hager and Hodkinson (2009) identify four conceptual lenses, or ways of understanding learning: the propositional learning lens, the skill learning lens, the learning through participation in human practices lens and the learning as transformation or reconstruction lens.

12 Although the participant uses the word "professional", the review is undertaken by a more experienced volunteer translator, who is not necessarily a professional translator (understood as one who translates for payment and commercially). 
"Best part has been the exchange of opinions with my reviewer and proofreader" (P5).

However, for one participant there were conflicting pressures between wanting to do well in order to receive praise from the reviewer, and being more relaxed about accuracy in the knowledge that quality was not entirely her responsibility:

... the fact that a proofreader is going to check your translation releases some of the pressure of translating. It is weird, if you do not have a proofreader you try to do it well because you don't want anything with mistakes published with your name on it. (P3)

On the one hand, the value of the quality control system inbuilt into the TED Translators workflows (O'Hagan, 2012) is acknowledged, but on the other hand, the limitations imposed by the rules and practices of the community are sometimes resented, as novice participants have not been part of their generation. This is the case with the requirement to use Global Spanish"13 (referred to as "neutral Spanish" in the quote below), which caused most of the errors in participants' work. The Spanish TED Translators community agreed that communication should be favored over the claims of any particular Spanish variety, and guidelines were drawn to that effect. Several participants ignored these guidelines and translated into Peninsular Spanish (choosing "vosotros" instead of the more widely used "ustedes"), causing reviewers to send back translations for amendment.

Still, disagreements with reviewers are not uncommon, and the system is set up to facilitate knowledge creation through dialogue between translator and reviewer, using the comments and personal message features in the platform as seen in this example of a participant challenging the reviewer's decisions: "I've written [to] him today about the last changes because I don't agree $100 \%$ and the translation seems to be already 'published"' (P5).

Finally, the value of incidental learning was also mentioned, alongside the learning of different topics that took place while translating or whilst

13 Global Spanish is understood in the TED Translators community as "that which seeks unity in diversity", by favoring communication and intelligibility, and denying the right of speakers of any variety of Spanish to impose their variety above others http://translations.ted.org/wiki/Spanish 
watching the videos to select one for translation, as exemplified by this comment on public speaking from one of the participants: "I realized how important is to control the way you talk when you do it in public specially controlling the pace and pauses" (P3).

\section{Motivation and Benefits}

The last set of questions asked participants to identify the advantages that engaging in this online volunteering activity might have for students of translation and for professional translators. Even though the question was phrased in positive terms, that is, participants were not asked to identify the disadvantages, it is worth noting the long list of advantages that were mentioned for students in particular, and the almost entire absence of disadvantages.

Developing translation skills and a first taste of subtitling as well as experiencing the pressures of professional translation were mentioned as positive outcomes of the activity. Exploring the content of the videos was also a positive for participants, allowing them to discover new fields, and to "learn about the world, hear different perspectives and events they never heard of, and hopefully open their minds a little bit more" (P3). Being able to learn without having to read was also mentioned as an advantage of continuing with this activity.

A valued and motivational aspect of contributing to TED Translators was the fact that the students' work would be reaching a global audience, for example:

- It was very motivating and rewarding the fact of knowing that my translation would be published and read by a great number of users world-wide (P2).

- Because we just finished our translation degree (some of us) and being given the opportunity to develop our skills in such an worldwide context is encouraging and exciting (P4).

Given their short experience in the field of translation, it appeared to be harder for participants to name possible advantages of contributing to TED Translators for professional translators - who in Cámara's (2014) survey of TED Translators volunteers accounted for $10 \%$ of respondents. Having a "relevant social role" (P2), broadening their knowledge and making "contacts that may help them with their professional life" 
(P3) were the only benefits mentioned. However, one participant had strong views on the undesirability of encouraging the perception that translation is something that is done for free, noting that "the same way the guy who sets up the microphone gets paid, the translator should as well" (P3). In that respect, her views are aligned with some in the profession who worry that the existence of online volunteer translation legitimizes the notion of free translation ( $\mathrm{O}^{\prime}$ Hagan, 2012)

There were also polarized views on the desirability of volunteering as a translator. Some highlighted the creation of civic value (Shirky, 2010) made through online volunteering, and the need for translation to transcend linguistic barriers (Beaven, Comas-Quinn, Hauck, de los Arcos and Lewis, 2013) to make knowledge more accessible globally:

- Within the globalization era we are living in, it is important to have all the information available and to spread it in a comprehensible way (P4).

- I believe that volunteering can have a positive impact on the community (P2).

However, one participant likened volunteering to internships as an unavoidable form of exploitation most graduates will experience before they can establish themselves professionally.

I've learned that I don't want to translate for free anymore even if it's a non-profit organization. [...] This is the second time I volunteer as a translator and I guess it's something we all go through, in other fields they get bad paid internships with which they have to live, as translators we get nothing but we can live anywhere and do it on our free time; in both cases it adds up to our resume. However, I think volunteer translation is devaluating our already highly devaluated profession $[\ldots]$ (P3).

\section{Conclusion}

This investigation has, in our view, generated useful insights into the opportunities and challenges of developing and implementing a Translation learning activity using an open online community, TED Translators. From our point of view as educators we have gained a better understanding of how some learners may perceive an activity based on volunteering negatively, in a context where some Translation scholars 
and professionals see volunteer translation as a threat to the profession. Conversely, feedback from participants "suggests that engaging in an authentic task and having their work published to the world is highly motivating, as is the opportunity of learning from a community of more experienced translators. Several also appreciated the civic value created by their work and their contribution to transcending linguistic barriers to make knowledge available more widely. On balance, there are more positive aspects in participants' feedback, and this leads us to believe that it is worth persisting in developing an open pedagogy (Wiley, 2013) using online volunteer translation communities and open tools. However, there are challenges inherent in combining informal and formal learning contexts, such as the ethics of mandating students to participate in volunteering activities or create open content (MartínezArboleda, 2014).

Beyond the learning derived from the experience, participants' feedback will also be used to improve systems and guidelines, reflecting the expansive learning model where shared action leads to changes in activity, agents, context and knowledge. The registration process in the subtitling platform is atypical and confused some participants, in spite of the comprehensive instructions, video tutorial, etc. This has an implication for learning design and the development of support and learning materials, given that learners are likely to expect technology to behave in the way they are used to from experience, rather than as described in the instructions. Robust technical support needs to be in place to ensure that technical problems do not mar the learners' experiences.

For the authors and for other Translation educators, the feedback received from participants will contribute to improve further iterations of this activity, for example, in ensuring that more guidance is given on how to establish a dialogue with reviewers. For Spanish, in particular, the need to use Global Spanish needs to be highlighted, and some discussion and critical engagement with this notion before the task could help learners understand the importance of this decision. A similar approach could be used to explore the place of volunteer translation in the landscape of practice, and its potential for translator education.

There are limitations in a study that has engaged a very small number of participants in a new type of learning activity that capitalizes 
on an existing online community of practice and its learning resources. However, as a means of exploring how education can harness informal learning systems, existing online communities and open tools, this project has helped us understand some of the challenges as well as the benefits it can bring to learners. It has also reinforced our belief that further research is needed on the intersection between formal and informal learning where using open tools and practices can provide learners with authentic, situated learning opportunities that make a contribution to society. 


\section{References}

Barkhuizen, G. and Wette, R. (2008), Narrative Frames for Investigating the Experiences of Language Teachers, System, 36, pp. 372-387, http://dx.doi. org/10.1016/j.system.2008.02.002

Beaven, T., Comas-Quinn, A., Hauck, M., de los Arcos, B. and Lewis, T. (2013), The Open Translation MOOC: Creating Online Communities to Transcend Linguistic Barriers, Journal of Interactive Media in Education, 3 (p. Art. 18), http://jime.open.ac.uk/jime/article/view/2013-18

Beetham, H., Falconer, I., McGill, L. and Littlejohn, A. (2012), JISC Open Practices: Briefing Paper, https://oersynth.pbworks.com/w/page/51668352/ OpenPracticesBriefing

Bekerman, Z., Burbules, N. C. and Silberman Keller, D. (2006), Learning in Places - The Informal Education Reader, New York: Peter Lang, http://dx.doi. org/10.1111/j.1548-1492.2010.01070.x

Braun, V. and Clarke, V. (2006), Using Thematic Analysis in Psychology, Qualitative Research in Psychology, 3(2), pp. 77-101, http://dx.doi. org/10.1191/1478088706qp063oa

Cámara de la Fuente, L. (2014), Multilingual Crowdsourcing Motivation on Global Social Media, Case Study: TED OTP, Sendebar, 25, pp. 197-218.

Coffield, F. (2000), The Necessity of Informal Learning, Bristol: The Policy Press.

Davis, B. and Sumara, D. (1997), Cognition, Complexity, and Teacher Education, Harvard Educational Review, 67(1), pp. 105-125, http://dx.doi.org/10.17763/ haer.67.1.160w00j113t78042

EMT Expert Group (2009), Competences for Professional Translators, Experts in Multilingual and Multimedia Communication.

Engeström, Y. (1987), Learning by Expanding: An Activity-Theoretical Approach to Developmental Research, Helsinki: Orienta-Konsultit.

Graddol, D. (2011), The Future of English?, The British Council, https://www. teachingenglish.org.uk/article/future-english

Hager, P. and Hodkinson, P. (2009), Moving Beyond the Metaphor of Transfer of Learning, British Educational Research Journal, 35(4), pp. 619-638.

Helsper, E. (2008), Digital Inclusion: An Analysis of Social Disadvantage and the Information Society, London: Oxford Internet Institute, http://dx.doi. org/10.1080/01411920802642371

Kiraly, D. (2005), Project-Based Learning: A Case for Situated Translation, Meta, 50(4), pp. 1098-1111, http://dx.doi.org/10.7202/012063ar

Kiraly, D. (2012), Growing a Project-Based Translation Pedagogy: A Fractal Perspective. Meta, 57(1), pp. 82-95. 
Kiraly, D. (2015), Occasioning Translator Competence, Translation and Interpreting Studies, 10(1), pp. 8-32.

Lave, J. and Wenger, E. (1991), Situated Learning: Legitimate Peripheral Participation, Cambridge: Cambridge University Press, http://dx.doi.org/10.1017/cbo 9780511815355

Livingston, D. (2006), Informal Learning: Conceptual Distinctions and Preliminary Findings, in Bekerman, Z., Burbules, N. C. and SilbermanKeller, D. (Eds.), Learning in Places: The Informal Education Reader, New York: Peter Lang.

Martínez-Arboleda, A. (2014), The Ethics of Student Digital Publication, Presentation given at the OER14 Conference, 29 April 2014, University of Newcastle, UK, https://oer14.oerconf.org/archive/14/oer14/92/view/index. html

Mitchell-Schuitevoerder, R. (2014), A Project-Based Syllabus Design Innovative Pedagogy in Translation Studies, PhD Thesis, Durham University, http:// etheses.dur.ac.uk/10830/1/R.E.H.Mitchell-Schuitevoerder_thesis_2014. pdf?DDD36+

O'Hagan, M. (2012), From Fan Translation to Crowdsourcing: Consequences of Web 2.0 Empowerment in Audiovisual Translation, in A. Ramael, P. Orero and M. Carroll (Eds.), Audiovisual Translation and Media Accessibility at the Crossroads, pp. 25-41, Amsterdam, NY: Rodopi.

Olohan, M. (2014), Why do you Translate? Motivation to Volunteer and TED Translation, Translation Studies, 7(1), pp. 17-33, http://dx.doi.org/10.1080/14 781700.2013.781952

Orrego Carmona, D. (2015), Using Non-Professional Subtitling Platforms for Translator Training, Rivista internazionale di tecnica della traduzione, 15, pp. 129-144.

PACTE (2005), Investigating Translation Competence: Conceptual and Methodological Issues, Meta, 50(2), pp. 609-619, http://dx.doi. org/10.7202/011004ar

Risku, H. (2010), A Cognitive Scientific View on Technical Communication and Translation. Do Embodiment and Situatedness Really Make a Difference?, Target, 22(1), pp. 94-111, http://dx.doi.org/10.1075/target.22.1.06ris

Ritzer, G. and Jurgenson, N. (2010), Production, Consumption, Prosumption: The Nature of Capitalism in the Age of the Digital "Prosumer", Journal of Consumer Culture, 10(1), pp. 13-36, http://dx.doi.org/10.1177/1469540509354673

Sfard, A. (1998), On Two Metaphors for Learning and the Dangers of Choosing Just One, Educational Researcher, 27(2), pp. 4-13, http://dx.doi. org/10.3102/0013189x027002004

Shirky, C. (2010), Cognitive Surplus. Creativity and Generosity in a Connected Age, London: Penguin. 
Sugimoto C. R. and Thelwall M. (2013), Scholars on Soap Boxes: Science Communication and Dissemination in TED Videos, Journal of the American Society for Information Science and Technology, 64(4), http://dx.doi.org/10.1002/ asi.22764

Tapscott, D. and Williams A. D. (2008), Wikinomics. How Mass Collaboration Changes Everything, London: Atlantic Books.

Vavoula, G. (2004), KLeOS: A Knowledge and Learning Organisation System in Support of Lifelong Learning, PhD Thesis, University of Birmingham, UK, http://www2.le.ac.uk/departments/museumstudies/about-the-school/ people/dr-giasemi-vavoula/Publications/downloads/publicationpreprints/ Thesis-GVavoula.pdf

Wenger, E. (1998), Communities of Practice: Learning, Meaning and Identity, Cambridge: Cambridge University Press.

Wenger-Trayner, E. and Wenger-Trayner, B. (2015), Learning in a Landscape of Practice: A Framework, in E. Wenger-Trayner, M., Fenton-O'Creevy, S., Hutchinson, C., Kubiac and B. Wenger-Trayner (Eds.), Learning in Landscapes of Practice: Boundaries, Identity, and Knowledgeability in Practicebased Learning, pp. 13-29, London: Routledge.

Wiley, D. (2013), What is Open Pedagogy?, http://opencontent.org/blog/ archives $/ 2975$ 